\title{
Gaps in Stewardship Quality at Three Institutions
}

Received (in revised form): January 8, 2003

\section{Angelique S.C. Grant}

Angelique S.C. Grant, Ph.D. is currently the Director of Development for the Princeton-Blairstown Center at Princeton University. She has been working in the development field for the past nine years and her area of specialization is major gift donor stewardship in higher education.

\section{Mimi Wolverton}

Mimi Wolverton, Ph.D. is currently an associate professor in the Department of Educational Leadership at the University of Nevada at Las Vegas. Her area of specialization is higher education administration.

\begin{abstract}
This research examines how major gift donors form expectations and perceptions of stewardship provided by higher education institutions. The findings were analyzed using an adaptation of Parasuraman, Zeithaml, and Berry's (1985) Quality Service Gap Model. The subjects in this research were major gift donors and development officers at three institutions in the western region of the United States. The three institutions were Big State University, a land grant university; Midsize University, a regional midsize public university; and Small College, a small private institution. Modifications to the Gap Model used in the study were based on a search of the literature, primarily from communication and marketing
\end{abstract}

\author{
Author's Contact Address: \\ Angelique S.C. Grant, Director of Development \\ Princeton University \\ Princeton-Blairstown Center \\ 330 Alexander Street, First Floor \\ Princeton, NJ 08544 \\ Tel: +1 6092583340 \\ Fax: +16092582624 \\ Email: grant@princeton.edu
}

theories (e.g., social exchange theory, norm of reciprocity, attribution and equity theories), as well as professional fundraising literature. A total of 30 major gift donors and 74 development officers participated in the entire study. Major findings in the study substantiate the existence of communication gaps, which reduce donor perceptions of stewardship quality at all three institutions. Recommendations for further study include expanding the study by creating a quantitative instrument to further assess stewardship efforts at other higher education institutions, as well as different types of fund-raising organizations (e.g., health service organizations, zoos, symphony orchestras, and so forth).

\section{Keywords:}

Fund raising, donors, stewardship, development officers, communication gaps, donor perceptions

\section{Introduction}

Private giving has become essential for many universities. Today, as never before, the difference between winning a race and 
being a higher education also-ran is often determined by a university's ability to successfully attract donations that can be used to improve program quality. ${ }^{1}$ Increasingly, a greater share of money raised in college, university, and private school campaigns derives from a few individual donors. Indeed, studies show that the 10 percent of donors who make the largest gifts typically account for 80 percent of any given campaign's total proceeds. $^{2}$

These high-end donors give to universities for all sorts of reasons. ${ }^{3}$ Motivations for giving vary from the psychological to the economic to the social, ${ }^{4}$ from heartfelt empathy to selfpromotion, from religious obligation to business networking. ${ }^{5}$ A large gift donor's motivations-the individual's ability, spirituality, and association with the charitable organization-parallel those of other donors regardless of their economic level. ${ }^{6}$ What is unclear, however, is what they expect in return. In particular, institutions assume that they understand how these donors define stewardship, and often institutions spend time and money engaging in activities they believe their donors value and regard as stewardship.

According to Kelly, ${ }^{7}$ the stewardship process includes reciprocity (consisting of appreciation and recognition), responsible gift use, reporting, and relationship nurturing. Stewardship completes the fundraising process and provides a loop back to the beginning of the fund-raising relationship so that a repeat gift will occur if the donor's gift has been properly stewarded. But are these activities important to donors, and do they reflect donors' and development officers' understanding of institutional stewardship?

This paper reports the findings of an exploratory study that examined the perceptions concerning stewardship practices of major gift donors and institutional development officers at three universities in the western region of the United States. Using an adaptation of a communication gap model, originally designed to discern whether customer perceptions of service quality mirrored those of providers, the researchers highlight mismatches between donor expectations of university stewardship and the actual practices in which these institutions engage. In effect, the study was designed to develop an understanding of the characteristics of stewarding major gift donor contributions in higher education. It explored the importance of stewardship and what it means to major gift donors, as well as to development professionals.

Kirkman argues that institutions engage in stewardship because "we are sincerely grateful for their gifts. Secondly, because we hope others will learn about those gifts and emulate them. And finally-our best prospects are those who have already given-because we want them to continue to support us with additional gifts." Stewardship of a donor needs careful thought, with specific initiatives selected to have special meaning. This is in fact the continuation of the cultivation cycle, as a person gains greater involvement and desires to make an even greater investment. ${ }^{9}$ As simply stated by Worth, "the best prospects for new gifts are past donors, and programs that provide careful stewardship and provide donors with timely information on the impact of their gifts can pay significant dividends in continued support" (p.13). ${ }^{10}$

The overall purpose of this study was to find out what major gift donors expect 
and experience after giving a major gift to an institution. More specifically, this research identifies what stewardship means to major gift donors and institutions of higher education. In the existing fundraising literature, stewardship has been defined as a form of reciprocity after a gift has been given (e.g., recognition, access to representatives of the institution, thank you letters, and so on).

The underlying motivation behind this study was to achieve a more informed conceptualization of stewardship that provides insights into donors' perceptions of whether an institution is meeting their expectations of stewardship. Three fundamental questions guided this study: how do major gift donors define stewardship? How do institutions define stewardship? And are institutions matching the expectations of donors?

\section{The Meaning of Stewardship}

Stewardship can be thought of as a philosophy and a means by which an institution exercises ethical accountability in the use of its resources. From this perspective, universities, usually represented by development officers, engage in an ongoing series of intentional activities (e.g., gift solicitation, gift acknowledgement, and further donor cultivation) designed to recognize donor involvement and safeguard donor investment in the organization. ${ }^{11}$

Blau expanded on Gouldner's norm of reciprocity with his theory on social exchange, which deals with "voluntary actions of individuals that are motivated by the returns they are expected to bring and typically do in fact bring from others." 12 In some respects, this second view of stewardship can be considered an exchange of sorts. ${ }^{13}$ Blau argues that "the satisfactions human beings experience in their social associations depend on the expectations they bring to them as well as on the actual benefits they receive in them." "14 These expectations are formed not only by past experiences, but also by learning what benefits others have obtained in comparable situations. In addition, he states that people become accustomed to a certain level of social gratification, and they come to take their initial gratification, which might have been extraordinary, for granted and expect at least that much from their associates in the future.

For instance, stewarding institutions offer various forms of explicit recognition, such as prominent publication of lists of donors, and other, even more tangible returns, such as enhanced seating at athletic or cultural events. These reciprocal recognition activities are known as forms of stewardship in institutional advancement. Although such returns can be costly to the institution, they are often believed to be worthwhile because their existence sometimes increases the frequency and amount of giving by potential donors. $^{15}$

Attribution theory has been useful in determining how and when dissatisfaction occurs with individuals. This theory was developed in social psychology to understand how individuals find explanations or causes for effects or behavior. ${ }^{16}$ When a service does not fulfill needs, the consumer will expect to find an explanation. Thus attribution theory provides an understanding of how consumers account for a disconfirmation of expectations. According to this theory, three key factors influence the nature of this explanation and ask the following questions: (1) stability (is the cause of the event temporary or permanent?); (2) focus 
(is the problem consumer-related or marketer-related?); (3) controllability (are these events under volition or are they uncontrollable?). ${ }^{17}$

Equity theory is another approach developed in psychology that has been useful in understanding consumer satisfaction/dissatisfaction. ${ }^{18}$ This theory focuses on the nature of exchanges between individuals and the perceptions of these exchanges. Equity theory can be applied to examine the exchange between donor and institution.

According to the equity theory, consumers form perceptions of their inputs and outputs into a particular exchange. They then compare these perceptions of the inputs and outputs to those of the salesperson, dealer, or company. For equity to occur there must be a perception of fairness on both sides of the exchange. The donor must perceive that the institution is being dealt with fairly in the exchange also (e.g., receiving adequate recognition for a gift).

Nevertheless, fairness perceptions tend to be self-centered, that is, biased more toward buyer outcomes and seller inputs than to buyer inputs and seller outcomes. ${ }^{19}$

Finally, fund-raising exchange theory suggests that stewardship is an essential part of the fund-raising cycle of identification, cultivation, solicitation, recognition, and monitoring of the gift. Stewardship, sometimes referred to as "donor relations," covers the entire relationship between a donor and the institution. In many cases, especially those involving major gifts, stewardship includes maintaining and cultivating a long-term personal relationship with donors, who, after all, are an institution's best prospects for future gifts. ${ }^{20}$
It is worth noting that often donors are reluctant to accept recognition for their gifts. But even when donors do seek recognition, there is nothing inherently wrong in bestowing recognition that is appropriate to the size and nature of the contribution, offered to other donors of similar gifts, and consistent with an institution's policies. ${ }^{21}$

\section{Examining Stewardship as Service}

Practically all organizations compete to some extent on the basis of service. There is not one industry that exists for which service matters are unimportant, but different organizations use service differently. For instance, the business community uses service to increase production, whereas educational institutions use service to recruit students, serve communities, and raise funds. Sasser, Olsen, and Wyckoff define a service as a package of explicit and implicit benefits performed with a supporting facility and facilitating goods. ${ }^{21}$ In addition, a service not only possesses tangible (high goods content) but intangible (little or no goods content) attributes as well. This intangibility makes service quality much more difficult to evaluate. Because of the absence of tangibility, most researchers agree that service quality is a measure of how well the service level delivered matches customer expectations. ${ }^{22}$

Stewardship, as carried out by institutional advancement units, is a type of service that institutions provide to their stakeholders. Parasuraman, Zeithaml, and Berry developed a service quality model that examines how consumers form expectations and perceptions of services provided by organizations. ${ }^{23}$ They investigated service quality in four service 


\section{CUSTOMER}

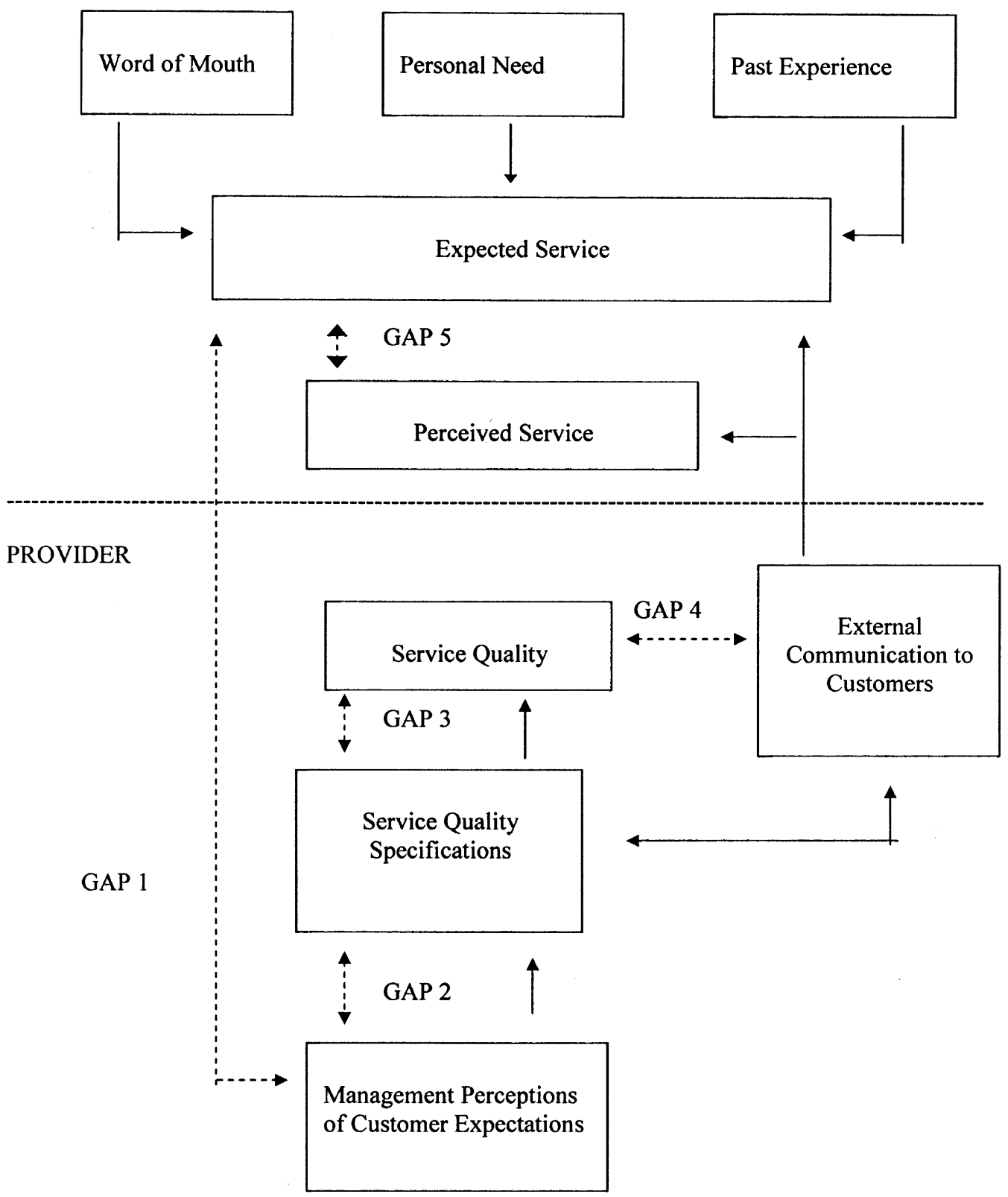

Figure 1: Conceptual Model of Service Quality (Zeithaml, Berry and Parasuraman, 1985) 
industries-insurance, banking, retail, and credit card companies-and identified five potential communication gaps. Gaps could exist in marketing, standards, performance, communication, and quality. The magnitude and direction of the first four gaps determine the quality of service delivered. The key to closing the final gap (quality) is to close the first four gaps and keep them closed. To the extent that one or more of the first four gaps exist, customers perceive service-quality shortfalls. ${ }^{24}$ Figure 1 visually depicts this model. Comparable gaps in the Stewardship as Service Model are:

- Gap 1: Donor Expectations: The difference between donor stewardship expectations and the institution's perceptions of donor expectations.

- Gap 2: Stewardship Standards: The difference between institutional perceptions of donor stewardship expectations and quality stewardship specifications, i.e., explicit (written) or implicit (accepted practice) standards that institutions set to fulfill these expectations.

- Gap 3: Stewardship Performance: The difference between quality stewardship specifications and stewardship actually delivered.

- Gap 4: Communication: The difference between donor experiences and what is communicated to them about stewardship.

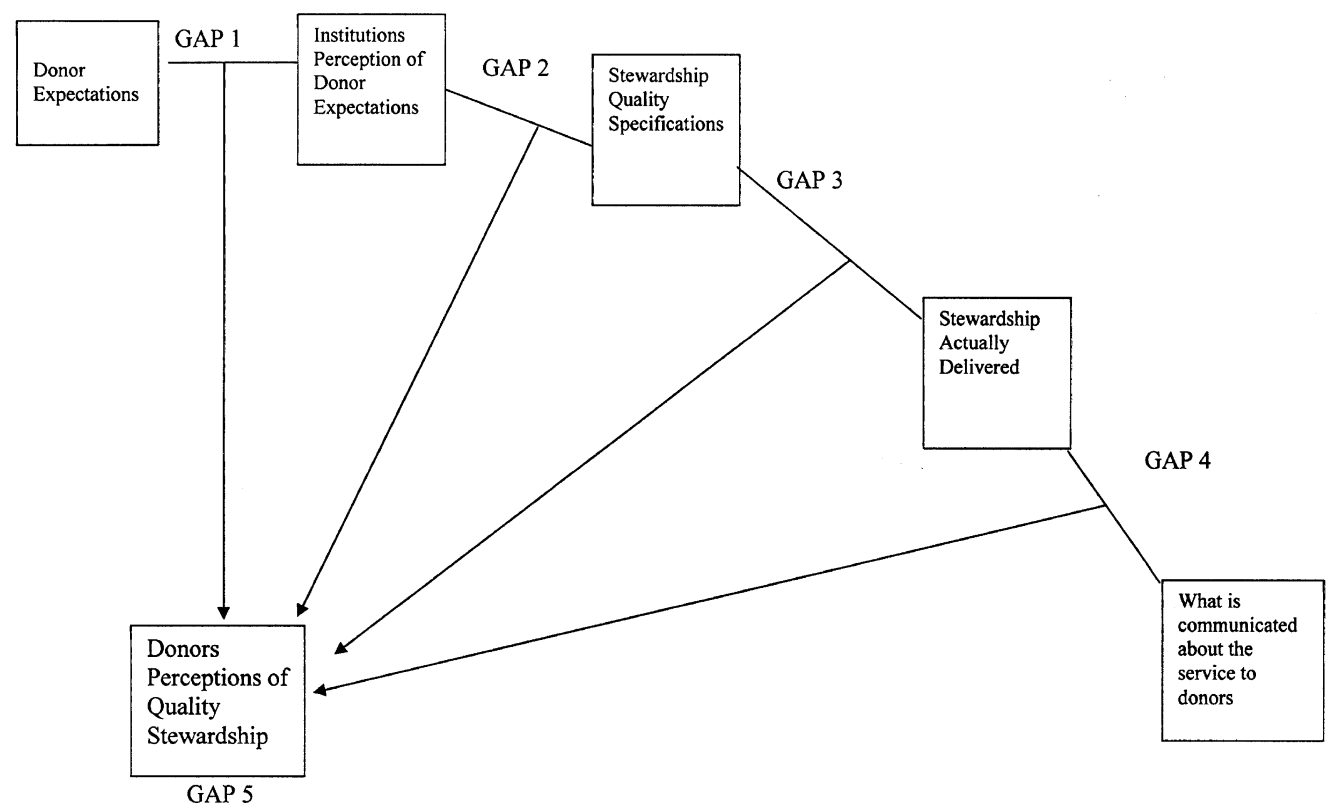

Figure 2: Adapted Stewardship Quality Gap Model

Gaps 1 through 4 indicate determinants of donor expectations. Gap 5 indicates donor perceptions of quality stewardship.

Adapted from Zeithaml, Berry, \& Parasuraman (1985) 
- Gap 5: Perceived Stewardship Quality: The difference between donors' stewardship expectations and perceptions of institutional stewardship efforts.

Figure 2 provides a schematic of the adaptation of the gap model to reflect stewardship quality.

\section{The Study}

This exploratory study used qualitative methods to explore donor stewardship expectations and institutional development officers' perceptions of donor expectations at three higher education institutions: Big State University (BSU), Midsize University (MSU), and Small College (SC). A multiple site study was selected because of the institutions' diverse student populations and varied institutional size and philosophical identities. The participants consisted of major gift donors who had established endowments of more than $\$ 10,000$, and/or provided at least one gift of $\$ 10,000$ to the institutions.

A nonprobable judgment sample (purposively) was used in this study. Since endowment donors are limited in number, they were purposefully selected from lists provided by all three institutions. Initially, endowed fund donors were targeted for the study because they represent a more fixed and compact list, have a long-term investment interest in the institution because of their commitment to establish an endowment, and represent the backbone of private donations to higher education. However, because access was available to very few endowment donors, several one-time major gift donors were also used in the study. Also, to fully explore the donor experiences, it was important to have a broad perspective. To accomplish this, the donor sample included different age groups, both genders, and donors from various academic backgrounds. Arrangements for selecting the sample were made with the assistance of university representatives at all three institutions.

Big State University was chosen because it is a fairly large land-grant institution located in the West. Midsize University was chosen because it is recognized as a high quality regional institution, and Small College was selected because it is a small private institution. Furthermore, participating universities were chosen because of their geographic proximity and feasibility, and because they represent a classic range of small to large institutions.

Data were gathered in two stages in the spring of 2000. The first stage entailed online interviews with university development personnel, and the second employed focus groups with major gift donors at each institution. In all, 40 donors and development officers were interviewed at BSU in April, 22 at MSU in July, and 12 at SC in May.

Focus groups were used to identify variables as they relate to donor perceptions of stewardship. These interviews helped identify conditions under which certain stewardship dimensions are manifested or expected. Appropriate prompts from researchers helped stimulate the discussions. In a few instances, participants, nevertheless, chose not to respond. In general, however, conducting focus groups at each institution provided a broad base of information from major gift donors.

In addition, online interviews of development officers were conducted. Although personal interaction with the development officers in the study was 
limited, using this mechanism increased their participation because many of the officers were in the field at the time of the study and unavailable for either face-toface interviews or focus group encounters. Comparing the two groups (donors and development officers) gave a truer picture of both parties' experiences. Four focus groups were conducted at the participating institutions, two at BSU (one with nine participants, the other with six) and one at MSU (nine participants) and SC (six participants). The development officers represented various disciplines on each campus including branch campuses.

During the focus group interviews, major gift donors were asked about their perspectives on stewardship. Researchers requested that participants address and answer stewardship questions based on the specific institution where their endowments were established rather than generally or based on stewardship activities of other types of organization, such as churches or the United Way. All focus group interviews were recorded and the tapes later transcribed.

Concurrently, development officer online interviews were conducted via email. Participants were asked to respond to seven open-ended questions about stewardship that were similar to those asked of donors. In addition, development officers were asked to provide and verify any institutional procedures regarding stewardship. Where written policies did not exist, development officers explained the unwritten, tacit policies in use at their institutions.

Analysis of the qualitative data was based on the process of categorization and descriptive analysis. ${ }^{25}$ Patterns emerged from the data; coding categories and a coding process allowed for comparison of development officer and donor perceptions of stewardship quality. Initially, within-institution analyses were conducted to discern whether perceptual gaps existed at the institutional level.

Later, across-institution analysis was also undertaken. In each instance, researchers employed the modified version of Parasuraman, Zeithaml, and Berry's service quality gap model as a lens for examining the data. 26

\section{Study Institutions}

Big State University is a land grant university with a combined undergraduate and graduate student population of 20,000 , an alumni population of 88,000 , 137,000 lifetime donors, and a 1999-2000 fiscal year giving total of over $\$ 50$ million. The BSU Foundation's development staff is comprised of 104 individuals working in a central-decentralized hybrid model.

Midsize University (MSU) is a comprehensive liberal arts university. Founded in 1899, MSU is one of six statefunded, four-year institutions of higher education with 11,655 full and part-time students, 555 faculty members, and over 65,000 alumni. The Midsize Foundation was formed in 1966 as a not-for-profit corporation, with a centralized staff of 13 development and support professionals who carry out the daily operations and conduct business on behalf of the University's Board of Directors. MSU's 1999-2000 Foundation's fiscal year total was roughly $\$ 25$ million.

Small College, founded in 1890, is recognized as one of the top private colleges in the region. It enrolls 2,000 students on the college's 200-acre campus. Its 115 full-time faculty members teach classes that average 25 students in size. Small College is known for both academic 
rigor and Christian commitment. Small College has a centralized development office, which employs six development professionals. Donors representing 26.6 percent of the alumni base, together with corporations and foundations, supported the institution with just under $\$ 6$ million in gifts over the last fiscal year.

\section{Gaps in Perceptions of Stewardship}

In the following section, potential gaps that the analyses revealed are presented for each institution individually beginning with BSU.

\section{Big State University}

The donors and development officers at BSU defined stewardship similarly. For instance, one donor stated, "It's taking care of assets by managing funds." Most of the development officers' responses indicated that the institution defined stewardship as the "act" of doing something to keep donors up to date and well-informed about the college/unit. As one development officer put it, "Keeping the donor actively engaged in what the college is doing with their funds ...."

Gap 1, donor expectations, did not exist because there was not a difference between donor stewardship expectations and the institution's perceptions of donor expectations. One donor stated, "I did expect to be informed somehow ... I expected to have some kind of report back from the institution every year of what had happened to the scholarship." In the same vein, development officers at BSU consistently understood that their donors wanted to be kept informed as to the disposition of their gifts. One development officer noted, "[People] appreciate reports, some visits, and [sometimes] contact with the students ... . We have a small college [within the university] and so [we] are able to visit with most of our large endowment donors at least annually; many of our reports are verbal, and this seems to be okay with most folks."

Ironically, however, Gap 2 existed because although donors indicated that the institution met their stewardship expectations, institution representatives felt that they did not meet donor expectations. One development officer said, "We partially meet some, for smaller gifts we do well. The more complex the gift the more complex the stewardship issues." Here, accepted (but unstated) institutional practices concerning stewardship seem to go beyond what development officers themselves do. In other words, donors expected to receive less than was assumed by development officers as protocol, and development officers believed that institutional efforts fell short of what should have been expected by donors.

Consequently, Gap 3 also existed. There was a major difference in what the institution specified would occur in regards to stewardship and what actually took place. Donors perceived that certain stewardship practices should exist and believed that they were not being met by the institution. One donor explained his past experience with establishing an endowment with the BSU Foundation and discussed how the endowment did not accrue enough money to award a $\$ 1,000$ scholarship.

We decided we wanted to give the [student] \$1,000 a year. We asked them [the development officers] how much money does it take to do that? They gave us some number; let's just say 
$\$ 20,000 \ldots$. Well all of a sudden, they notified us that the student is only going to get $\$ 800$ this year. So I say, why? Why are we short? [The development officer responded], Well we started taking one percent for handling? So I said "What do you mean handling? The money's sitting there in a bank. All you have to do is take $\$ 1,000$ out and give it to the guy [student]. We have to take our cut [the Foundation's response]; and I'm thinking wow, how many scholarships [are there] and what would those cuts amount to?

Another donor adds, "If the endowment is not producing enough to really help these kids, I can probably add to this annually. I just like to know how it is doing. And it would be nice if a person knew somewhat where all this percentage goes [referring to the handling fee]. I never thought about the hundreds of millions of dollars that's in this pool." One development officer explains why donors do not receive this type of information. "It [stewardship] is very hands-on and time consuming ... [and] no one is specifically dedicated to stewardship. Because stewardship activities typically don't have a deadline, they can be the last to get done."

The communication gap (Gap 4) existed because there was a difference between donors' experiences and what was communicated to them about stewardship. The BSU Foundation pamphlet entitled, "Named Endowment Opportunities," provides general information about the benefits of establishing an endowment at the institution, endowment levels, ways to create an endowment, income tax deduction information, the institution's endowment growth chart, and recognition a donor would receive if he or she were to establish an endowment, but does not directly address stewardship activities. In this regard, one donor suggested, "Nothing was communicated. We just set up the endowment according to the document and that was it. We felt that we were going to hear something soon, but nothing was directly communicated to us about the stewardship part of the gift." In stark contrast, a development officer noted, "We usually explain what they can expect in the way of stewardship while we are discussing their making the gift." However, other development officers and donors alike suggested that there was a lack of consistent communication about gift stewardship at the university.

In general, Gaps 2, 3, and 4 and, as a consequence, Gap 5 (stewardship quality) existed at BSU.

\section{Midsize University}

The donors at MSU defined stewardship as the management of resources. One donor noted, "I think of stewardship as someone's talent, in the Bible the utilization of what you have put to its best uses ... . But in any instance, stewardship to me is the best possible use of your resources." The development officers did not provide a formal definition of stewardship, but indicated that they see stewardship as a "process" of rewarding donor generosity through a series of activities (e.g., special events, thank you letters, etc.). "To my knowledge, we do not have a formal definition for stewardship."

Gap 1, donor expectations, did not exist. Both donors and development officers indicated that donors expected to be thanked and recognized and that the 
institution should properly manage gifts given to the institution. As noted before, development officers viewed stewardship as a process, and donors focused on gift management. In some respects, each definition exists within the other. One development officer summarizes, "Our donors expect to be thanked ... be publicly recognized ... to be kept in the loop of things, and to be considered an insider in the life of the institution." Donors indicated that, for the most part, they were very satisfied with institutional stewardship efforts, but still raised a thought-provoking question: "I think the Foundation has met my expectations, [but] you have to ask the question: what were your expectations to start with? I've always learned that if you expect very little out of people, anything you get is a plus; but if you expect too much out of people, your disappointments are too great in life ...."

At MSU, Gap 2, stewardship standards, assessed the difference between the institution's perceptions of donor expectations and the standards (written or tacit) the institution set forth to fulfill these expectations (quality stewardship specifications). The institution's perception of donor expectations suggests a process embedded with activities (e.g., acknowledgements, special events, personal visits, etc.) as well as proper management of the gift. However, there are no formal definitions, standards, or policies in place in terms of institutional stewardship. Therefore, the quality of stewardship varied from donor to donor. It depended on the level of the donor and their gift to the institution. For example, if a policy stated that each major gift donor would receive a thank you note, two endowment updates, and three personal visits a year, then a set standard is in place at that institution. However at MSU, donors slipped through the cracks of the "process" because each donor did not receive the same treatment from the institution. Development officers admitted that the institution "partially" meets donor expectations: "I think expectations are partially met for most major donors. Our development staff is exceedingly lean, which accounts for our minimal approach to stewardship." Another stated, "I think we partially meet expectations ...

Obviously, some donors need more attention than others and I'm sure we could do a better job working with those types of donors." Because no set institutional standards existed at MSU and treatment of donors varied, Gap 2 existed.

As a result, Gap 3, stewardship performance, also seemed to exist. One development officer explained, "I would like us to develop more ways to involve donors with faculty and students. We do well with scholarship donors and students, but could do much more with endowment donors that create program rather than scholarship endowments." Another noted, "[We should] afford donors the

opportunity to interact with the recipients of their funds (students and faculty) ...." Although donors did not seem to expect this type of interaction, Gap 3 existed primarily because development officers believed that it did.

Gap 4, communication, also existed. During the focus group interviews, donors in attendance did not comment on what was communicated to them from the institution, even when prompted to do so by the moderator. Instead, they posed questions regarding the Foundation's assets and about administrative costs, suggesting a lack of knowledge that could 
only be gained through ongoing communication with the Foundation and its willingness to divulge this kind of information. For instance, one donor asked, "Did you get any idea about what percentage of the foundation's assets were used for administrative costs?" Another donor responded, "I don't know." The first donor suggested, "That would be interesting to know because we could use that sort of information; I'd like to know what the mean and the average is."

In distinct contrast, development officers said that they do discuss the endowment program with donors. "We communicate personally and individually with donors, letting them know what is happening with their gifts as well as on campus. They also receive publications (e.g., endowment reports, president's reports, etc.) and are invited to campus events. I think the overall message to every donor is consistent and reflects the values and ideals of the university." The lack of specific knowledge about

Foundation assets and operating costs as they pertain to specific donor gifts could possibly be a recollection issue, where donors had been informed of this information but could not remember the information at the time of the focus group interviews. Or it could stem from donors not understanding the stewardship literature sent to them from the institution, as well as not fully understanding the discussions that they had with development officers. No matter what the reason, donors perceived a communication gap: that indeed, they were not well advised about how the Foundation uses monies that are donated to MSU.

Because Gaps 2, 3, and 4 seemed to be present at MSU, Gap 5, perceived stewardship quality, also existed. Even though donors indicated that the institution satisfactorily stewarded them as major gift donors, MSU did so because donors held no firm stewardship expectations. As a consequence, although donors were not cognizant of the fact, stewardship efforts at MSU were not carried out at the level that they should have been and efforts at the institution could be improved to some extent.

\section{Small College}

For the most part, donors and development officers at SC defined stewardship similarly. Development officers indicated that stewardship meant keeping the donor informed on how the gift was used. "The working definition for the Foundation ... is the care and maintenance of our relationships with our donors and income beneficiaries. This is expressed (or should be) in every aspect of our work; including the timeliness of our trust distributions and tax information, keeping our donors connected via information about the institution, and generally making routine contacts with each of them." Donor comments confirmed this understanding of stewardship. "Stewardship is getting back to the donor and letting them know what's been going on." As in the cases of BSU and MSU, development officers at SC understood what their donors expected. As a consequence, Gap 1, the difference between donor expectations and institutional perceptions of those expectations, did not exist.

Although both the donors and institution agreed on the satisfaction level, it does not mean that some type of gap did not exist. Interestingly, development 
officers at SC suggested that the institution needed to improve its stewardship efforts and do a better job. "I do think we could improve in our reporting and do a better job of tying our scholarship recipients to the donors." Still others spoke of doing "a better job of stewarding our establishment of fund documents and using these to better connect our constituents to the institution in an academic sense. I believe that we could use a bigger budget to steward our major gift donors." Admissions like these suggest that the stewardship standards Gap 2 existed. The institution had no set standards (written policies) for fulfilling the stewardship obligations that donors expected.

Because of this lack of stewardship standards and or policies, donor stewardship fell through the cracks of the process, indicating that Gap 3 was also present. One donor explained her experience after giving a major gift to the music library.

I included funds to hire someone to catalog CDs that were to be purchased as part of the gift. And, of course I expected them to do it, but they didn't for a very long time. When I gave the gift I was completely ignorant about the process, so when one of the teachers came to me and said we need another $\$ 1,300$ for more stereos to play the CDs on, I wrote the check. Six months later I got a telephone call from somebody who said, "We were cleaning out the office and found your check for $\$ 1,300$ made out to the school." The teacher I gave the check to left the check at the school, which then fell on the floor, and the janitor found it. The janitor asked me, "What's [the check] for?"
Another donor chimed in with her experience after establishing a student travel grant.

I assumed that they [development office] would take care of it. But they did not alert the academic department that they had the money until two years after I gave the gift. I asked a professor at an airport in Chicago, "How are the students using the travel grant?" He said, "What travel grant?" So, I had to contact the department and I was very embarrassed.

A third donor commented, "Maybe it's an unusual occurrence." But another interjected, "Well, we've got six people here and it's [lost gift checks and gifts] happened twice; hmm, must not be that unusual."

\section{A definite lack of communication} occurred between donors and development officers at SC, which led to Gap 4, communication. Overall, there were different levels of understanding within the group of donors interviewed. Some donors were familiar with endowments and how they worked. One couple had made a planned gift and had received information from the Foundation regarding their gift. But some donors were not provided clear, consistent stewardship information by the institution. "If you give to the Foundation, then you have follow up, but if you give directly to the college, and it's not through the Foundation, you don't." This statement, alone, suggests a lack of understanding on the part of donors about the giving process at SC because all gifts are processed through the development office regardless of which unit receives the gift. Development officers admitted that a communications gap existed. "We do not 
have any written communication regarding stewardship that our donors receive. Verbally, they are told that if they establish an endowment, we will report to them annually on the growth and balance of the fund, and if they've established a scholarship, we let them know that we will communicate with them regarding the recipient of their scholarship." However, whether these interactions take place on a regular basis remains unclear.

For the most part a perceived stewardship quality Gap 5 existed at SC. Because a tremendous amount of donor confusion existed, perceived stewardship quality suffered. Although donors had high admiration for the institution, as well as the individuals that they worked with in the development office, numerous donors suggested that stewardship expectations were not met by the institution.

\section{Discussion}

\section{Big State University}

At BSU, some of the lack of consistency in stewardship efforts could be attributed to a high turnover in staff and the centralized-decentralized hybrid model used at the BSU Foundation. Major gift donors had varied experiences (one at the department or college, another at the central office) due to the organizational structure. Because there was no set standard way that development officers were required to steward donors, stewardship of major gift donors varied across the institution. At times during the focus group interviews, there was a great deal of confusion as to who provided the thank you letters, endowment information, and so forth. Different levels of stewardship existed; different styles of communication were employed. If the institution set specific stewardship standards with donors and enforced those standards across colleges and departments within the institution, communication would improve and donors would know up front what to expect when it comes to stewardship.

Thus far, the institution has managed to do a reasonable job at stewarding donors, especially during the last major campaign; however, there seems to be a concern among donors and development officers that the stewardship efforts are declining. BSU development officers felt the current environment encouraged an attitude that gaining new donors was more important than stewarding existing donors.

\section{Midsize University}

The donors indicated that they had low expectations of the institution's stewardship efforts and stated that the low expectation level was the reason why they were satisfied with the stewardship efforts of the institution. In contrast, the development officers indicated that the donors were unsatisfied with the stewarding efforts of the institution. This strong contrast explained why perceptual gaps existed at MSU. The institution's perceptions of donors' experiences and expectations were definitely inconsistent. Unlike BSU, MSU's development officers felt that the institution was putting resources into stewardship efforts and indicated that the institution's strengths included the communication/relationship between the donors and development officers. However, several development officers admitted that the institution needed to develop a strategic plan for stewardship. 


\section{Small College}

Initially one would think that because of SC's size (small in relation to the other study institutions) its stewardship efforts would be more effective. However, because of its size SC has a smaller staff. As a consequence, the ratio of development officers to donors was similar to that at the Big State and Midsize and the same challenges existed.

SC did not have a stewardship policy (official or implicit), which means that the stewardship experiences of the donors differed across the board. In this instance, donors have been falling through the cracks of the existing stewardship efforts of the institution. In addition, the same issues that the other institutions faced with regard to stewardship existed with SC. For instance, not enough staff: "as we gain more donors, we are becoming shortstaffed ...." Additionally, the donors lacked knowledge of endowment details, and they had not been informed regularly about the status of their personal endowments.

\section{Comparing the Institutions}

The three institutions used in this study are each unique, yet similar. First, all three institutions researched are located in the same region. Second, two institutions (BSU and SC) share the same minimum endowment level of $\$ 25,000$-meaning a donor must give at $\$ 25,000$ or more in order to establish an endowment with those institutions. MSU's minimum endowment level is $\$ 20,000$. Third, although institutions varied in size, their primary donor and student bases are located in the same region. The only difference among the three institutions, other than the size of the institution, was the organizational structure of the development units, with BSU having the only centralized/decentralized organizational model.

Interestingly, regardless of the differences in the endowment levels at the respective institutions, concerns about proper stewardship of donor gifts remained the same. In addition, institutional size did not seem to make a difference in stewardship efforts, nor did the organizational model affect those efforts. At each institution, very similar themes emerged. Each theme suggested a missing piece in institutional stewardship: lack of standardization in stewardship efforts, inconsistency in efforts because no standards existed, and poor lines of communication with donors.

Institutions were aware of the donors' expectations (as evidenced by the nonexistence of Gap 1 at all three institutions). However, not one institution fulfilled that expectation (Gap 2). Because no standards for stewardship efforts existed at BSU, MSU, or SC, donors at all three institutions met with stewardship efforts that did not fulfill their needs (Gap 3). Donors at all three institutions mentioned that the most important stewardship activities are: being thanked, notification as to how the funding was used, consistent communication, and provision of endowment information (Gap 4).

Because several perceptual gaps existed at each of the study institutions, room for improvement in their stewardship efforts existed. By minimizing these gaps, these institutions can improve the perceived (and real) quality of their stewardship efforts (Gap 5).

\section{Implications for Practice}

Although the reported study was conducted at three institutions in one 
region of the USA, it is likely that other colleges and universities might suffer similar shortcomings. In the following section, we suggest ways in which universities might address the perceptual gaps identified by the model.

\section{Donor Expectations Gap}

Even though this first perceptual gap was not present at the three study institutions, we believe that other universities could experience it. We therefore include it in our recommendations. Providing high quality stewardship means that an institution knows what its donors expect. Often, institutions overlook or underestimate donors' needs. The key to closing Gap 1 is for the institution to know its donors and know what they expect. This could be done via research. Not many institutions engage in research regarding donor attitudes; however, such research is a primary vehicle for understanding donors' expectations and perceptions of stewardship. This research can be carried out by developing donor focus groups, tracking donor comments, and finding out what other peer institutions do to assess donor expectations.

\section{Stewardship Standards Gap}

Although an institution might understand what donors expect (Gap 1), it also must now figure out a way to use this knowledge to set stewardship standards for the institution. Gap 2 seems to have occurred because institutions felt as if there was no need for stewardship standards. It could have also occurred because senior level administrators often cannot or will not change internal stewardship systems to enhance stewardship quality. Doing so often requires altering the very process by which donors are obtained. It takes time to focus on quality stewardship, which in turn takes away from time spent cultivating new donors. As one development officer at BSU stated, "Sometimes, it is easy to get working on future gifts to the exclusion of past gifts." Standardizing the stewardship process and obtaining the managerial commitment to quality stewardship can close Gap 2.

\section{Stewardship Performance Gap}

Gap 3, which is often called the ServicePerformance Gap, ${ }^{27}$ occurs when stewardship provided by the institution is ambiguous. This gap occured because the role of the development officer is defined not only through the expectations of donors, but by demands to generate new donors and pressure from other administrators (e.g., supervisor, senior level development officers, etc.) who have vested interests in how they perform their jobs and how much money they raise.

This gap also occurred because development officers felt that they simply did not have the ability to perform at the necessary levels. They could not meet the demands of the position both internally and externally. This is due to lack of staffing, high turnover in the development profession, and sometimes even lack of training. One development officer bluntly stated, "We need more staff to fulfill stewardship responsibilities ...." Another suggested, "The biggest weakness is that we do not have a staff member who devotes 100 percent time to stewardship.” Because stewardship is often low on the priority list, "it can be the last thing to get done." Jeavons asserts that stewardship is often thought of as a narrowly focused activity of the basic management of funds. He 
proclaims that, "real stewardship has inescapabably moral obligations and responsibilities." 28

\section{Communication Gap}

Whether through publication or promise, it is important to steward donors at their expected levels. Gap 4 occurred because institutions neglected to keep donors informed. Even when the information was available to donors, development officers did not necessarily provide it to donors. Donors do not always know what questions to ask. They trust institutional representatives to keep them apprised of the situation.

Donors' perceptions of quality stewardship can also be influenced either by raising donors' perceptions or by lowering expectations. Managing donors' expectations, especially those created by the institution through external communications, is an essential part of a strategy to attain perceived quality stewardship. The expectations that donors bring to stewardship affect their evaluations of its quality: the higher the expectation, the higher the delivered service must be to be perceived as high quality.

The donors indicated that they were satisfied with institutional stewardship efforts but suggested that, "If you expect very little out of people, anything you get is a plus." Taking the high road by raising donor expectations and then meeting them may in the long run reap the benefit of more donations. Letting donors know what is and is not possible and the reasons why also helps donors establish realistic stewardship expectations.

\section{Stewardship Quality}

In the Gap model, the gap between donors' expectations and perceptions of quality stewardship (Gap 5) results from the existence of four gaps on the institution's side of the model. Each of the four institutional gaps (Gaps 1 through 4) in turn is caused by factors associated with that gap (see Figures 1 and 2). Is one gap more critical than the others in affecting the perceived quality stewardship? The exploratory nature of this study leaves this question unanswered. Intuitively, however, it seems that gaps, when they exist, must be closed in the following order: donors' expectations must be understood (Gap 1) before the institution can set appropriate standards (Gap 2) and development officers must steward donors (according to set standards across campus) in order to close Gap 3. Attempts to close Gap 4 through effective communication will impact efforts to diminish the existence of the first three gaps. Minimizing all four improves an institution's chance of enhancing donor perceptions of stewardship quality (Gap 5).

\section{Implications for Future Research} A great deal of information was obtained as to how donors view stewardship. Both development officers and donors discussed their expectations, priorities, experiences, and satisfaction levels. Common patterns that were discovered offer insights into how donors define and evaluate institutional stewardship. The next research step might be to take the results of this study and begin the process of developing a diagnostic tool: an instrument for measuring perceptions of quality stewardship. Measurable variables could range from communication perceptions (e.g., consistent vs. inconsistent) to gift use notification. Such an instrument could provide universities with valuable information about donor 
perceptions of their stewardship efforts. Research could also be expanded to other areas of fund raising, for instance annual giving, planned giving, and gifts-in-kind donors. In addition, future studies could explore stewardship's role in the cultivation process leading to a repeat gift. Finally, since there is very little fundraising literature and research available, stewardship research should be explored in other types of organizations (e.g., hospitals, zoos, museums, social service agencies, community colleges).

\section{Conclusion}

As Dessoff suggested, stewardship represents a form of continued cultivation of donors. Institutions must thank donors, keep them informed, and be good stewards of the money they give them. ${ }^{29}$ The clearer an institution is about its stewardship standards the higher the quality of stewardship offered by that institution. Assuming that stewardship efforts meet donor expectations without determining whether they actually do may be a dangerous practice, but one in which colleges and universities unintentionally engage. Assuming that donors understand what good stewardship is can also be lethal. Major causes abound, and major donors exist in limited supply.

Systematically learning an institution's stewardship strengths and weaknesses and acting on that information may provide colleges and universities a leg up in their ability to attract and retain major donors.

\section{References}

1. P. Shriver (1980), "What private money does: The impact of private investment on public colleges and universities," Report No. HEO12590, Office of Research \& Information National Association of State Universities \& Land Grant Colleges, Washington, DC.
2. Chronicle of Philanthropy (1999), "Top donors dominate big educational campaigns," <http:// philanthropy.com/premium/articles/v12/i05/ 05002801.htm>.

3. J. Syme (1998), "An analysis of major donors to Washington State University," Unpublished masters thesis, Washington State University.

4. B. Hopkins (1991), The Law of Fund-Raising, John Wiley \& Sons, New York.

5. P. Schervish (1997), "Major donors, major motives: The people and purposes behind major gifts," New Directions for Philanthropic Fundraising: Developing Major Gifts, 16, Summer, pp. 85-112.

6. Ibid.

7. K. Kelly (1997), Effective Fund Raising Management, Lawrence Erlbaum, Mahwah, NJ.

8. K. Kirkman (1995), "Thanks again-and again," CASE Currents, September, pp. 38-40, quote p.39.

9. P. B. Smith (1997), "Managing successful major gift programs," in New Directions for Philanthropic Fundraising: Developing Major Gifts, 16, Summer, pp. 31-47.

10. M. J. Worth (1993), Educational Fund Raising: Principles \& Practice, American Council on Education and Oryx Press, Phoenix, AZ, p.13.

11. Fund Raising School at Indiana University (1995), "The development process," Unpublished report, The Fund Raising Institution, Indiana; D. Hopkinson (1995), "Thanks for everything," CASE Currents, August, pp. 20-3.

12. Gouldner, A. (1960), "The norm of reciprocity: A preliminary statement," American Sociological Review, 25, April, pp. 176-7; P. M. Blau (1986), Exchange and Power in Social Life, revised edn., Transaction Books, New Brunswick, NJ, p.91.

13. B. E. Brittingham and T. R. Pezzulo (1990), "The campus green: Fund raising in higher education," ASHE-ERIC Higher Education Report No. 1, George Washington University, School of Education and Human Development, Washington, DC.

14. Blau (1986), Exchange and Power in Social Life, op. cit, p.142.

15. D. Elliott (1995), The Ethics of Asking: Dilemmas in Higher Education Fund Raising, The Johns Hopkins University Press, Baltimore, MD.

16. R. Mizerski, W. Richard, L. L. Golden, and J. B. Kernan (1979), "The attribution process in consumer decision making," Journal of Consumer Research, 6, 2, pp.123-40.

17. Ibid.

18. E. Walster, G. W. Walster, and E. Berscheid (1978), Equity: Theory and Research, Allyn and Bacon, Boston.

19. R. L. Oliver and J. E. Swan (1989), "Equity and disconfirmation perceptions as influences on merchant \& product satisfaction," Journal of Consumer Research, 16, 3, pp. 372-83. 
20. A. L. Dessoff (1997), "Put it in writing," CASE Currents, February, pp.30-4; Hopkinson (1995), "Thanks for everything."

21. Elliott (1995), The Ethics of Asking, op. cit.

21. W. E. Sasser, J. Olsen, and D. D. Wyckoff (1979), Management of Service Operations: Test and Cases, Allyn and Bacon, Boston.

22. R. C. Lewis and B. H. Booms (1983), "Marketing aspects of service quality," in L. L. Berry, G. L.

Shosack, and G. Upah (Eds.), Emerging Perspectives on Services Marketing, American Marketing Association, Chicago; C. Gronroos (1982), Strategic Management \& Marketing in the Service Sector, Swedish School of Economics \& Business Administration, Helsingfors.

23. A. Parasuraman, V. Zeithaml, and L. Berry (1985), "A conceptual model of service quality and its implications for future research," Journal of Marketing, 49, pp. 41-50.
24. V. Zeithaml, A. Parasuraman, and L. Berry (1990), Delivering Quality Service: Balancing Customer Perceptions \& Expectations, The Free Press: New York.

25. M. B. Miles and A. M. Huberman (1984), Qualitative Data Analysis: A Sourcebook for Nerw Methods, Sage Publications, Beverly Hills, CA.

26. Parasuraman et al. (1985), "A conceptual model of service quality," op. cit.

27. Ibid.

28. T. H. Jeavons (1994), "Stewardship revisited: Secular and sacred views of governance \& management," Non-Profit \& Voluntary Sector Quarterly, 23, 2, pp. 107-222, quote p.115.

29. Dessoff (1997), "Put it in writing," op. cit.

\section{Practitioner's Perspective}

Author and consultant Nido Qubein told a CASE audience that he says to business and education leaders, "You can determine the price for your services and products, but it is the customer who determines the value." If the customer, in this case the donor, determines there is sufficient value in what can be delivered, a linkage is formed. How that value is communicated and maintained afterward is the essence of stewardship.

Grant and Wolverton's topic lies at the heart of what we do in advancement. I have always defined stewardship in simple terms: making people feel good about what they have done with and for us. This concept is straightforward in theory yet complex in practice. At the three institutions studied by the authors, probably representative of many others, stewardship efforts often fall short of intended goals.

While I found many elements of their research to be interesting, I was particularly drawn to the authors' articulation of performance gaps; specifically how these differences between expectations and actual delivery of service come about. They identified gaps in donor expectations, institutional perception of donor expectations, stewardship goals and policies, what was actually delivered, and finally, how this shaped the donors' perception of the quality of stewardship. These chasms occurred for several reasons, including:

- stewardship policies and procedures were not carefully defined, therefore delivery was inconsistent; expectations differed between donors and staff (this included practices such as not effectively communicating to the donors about administrative fees on endowments, when the first income would actually be used, how often the donors would receive stewardship reports, and even lack of communication between the advancement office and other units for which contributions were intended);

- advancement staff had great ideas and some policies in place, creating high 
expectations among donors, but didn't deliver because of staff turnover or because more pressing issues took precedence over stewardship;

- some donors overlooked materials that were sent and therefore perceived that they weren't sufficiently informed about the use and impact of their gifts.

- Finally, the authors suggest there is some advantage in addressing your stewardship shortcomings with some degree of organization, that is, "close the gaps in order."

We should:

- understand the donors' expectations (actually ask them individually, in focus groups or through surveys what they would like to hear from you about their gifts);

- establish appropriate standards, policies, and procedures (and make sure all staff know about them);

- guarantee that policies and procedures are followed (do not let the need to engage new donors make you overlook the ones you already have);

- communicate effectively with donors (let them know what to expect from you, then set up a tickler system that reminds you to call, write, visit, or otherwise involve them appropriately).

If all of the above are done well, the donors will perceive that they are important and are receiving the proper stewardship from your institution-they will simply feel very good about having invested their contributions and their time with you. 